\title{
The Specific Features of Psychological Condition Nomination as the Discourse Index in the Contemporary Russian Language
}

\author{
[Специфика номинации душевных состояний \\ как дискурсивный маркер в современном русском языке]
}

\author{
Liliya R. Akhmerova - Gelinya Kh. Gilazetdinova
}

\section{DOI: 10.18355/XL.2015.08.04.15-23}

\begin{abstract}
Аннотация
Статья посвящена проблеме номинации душевных состояний в современном русском языке. Этот процесс затрудняется абстрактной семантикой слов, эксплицирующих в языке психологическое состояние, а также сложными отношениями человека с миром собственной психики. Вероятно, можно говорить о существовании в современном русском языке особого «психологического» дискурса. В обоих его типах (психотерапевтическом и обиходном психологическом дискурсе) предпочтение различных способов экспликации душевного состояния и их разная коммуникативная значимость говорит об избирательном отношении говорящего к акту подобной номинации и свидетельствует об интеллектуальности коммуникативной эмоциональности.

Ключевые слова

семантика, эмотиология, дискурс, номинация, коммуникация, вербализация эмоций
\end{abstract}

\section{Введение}

Современный человек живет в мире эмоций, определяющих качество его жизни и его самоощущение, однако не в мире с самим собой. Это внутреннее беспокойство и внимание человека к собственной психике делаются своеобразным знаком нашего времени и проявляются в популярности прикладной психологии, издании большого количества психологической литературы и востребованности услуг психотерапевтов и психологов. Однако верным будет заметить, что человек живет в мире оязыковленных чувств и эмоций, поскольку его существование как человека невозможно вне «языкового круга».

Объективная психологическая реальность душевных переживаний не вызывает сомнений. Более того, люди как представители одного биологического вида наделены одним и тем же мимическим аппаратом, позволяющим представителям различных культур понимать эмоциональное состояние друг друга. С биологической точки зрения, носители разных языков могли бы жить в одном эмоциональном мире (Ekman, 2003), однако «языковой круг» является своеобразной преградой между миром физиологических эмоций и эмоций оязыковленных, пропущенных сознанием через фильтр языка (Wierzhbicka, 1999).

По утверждению Б.Ю. Нормана, «вся та система понятий, которой обладает современный человек, покоится на системе названий» (Norman, 2004: 78). Феномены душевного мира человека при всей своей психологической реальности очень абстрактны, вербализация позволяет им стать полноправным сектором «языкового круга» в качестве важнейшего семантического поля, однако отношения между миром души и миром языка сложны и противоречивы, и именно этот момент может стать ключевым в понимании психологических трудностей современного человека. 
А. Вежбицкая сформулировала этот до сих пор не потерявший актуальности вопрос эмотиологии таким образом: «Верно ли, что названия эмоции являются ярлыками для эмоций, существующих независимо от них, или они содействуют созданию эмоций (путем наложения интерпретации на эмоциональное переживание и выдвижения определенных допущений, норм и ожиданий, которые могут управлять поведением и регулировать взаимоотношения между людьми)?» (Wierzbicka, 1997: 343).

Эта «смысловая нагрузка» сделала языковые выражения психических состояний востребованным объектом исследования - они изучались и как значимый элемент лексико-семантической системы языка в аспекте синхронии и диахронии (Л.Г. Бабенко, Ю.И. Гамаюнова и др.), и с позиции лингвокультурологии как общекогнитивный феномен (А. Вежбицкая, В.Н. Телия, Ю.Д. Апресян, Н.Д. Арутюнова, Н.А. Красавский и др.), и в широком ономасиологическом смысле с точки зрения категоризационного подхода (В.А. Косова), и в рамках эмотиологии как целостного раздела лингвистики (В.И. Шаховский). Так, по мнению В.И. Шаховского, «проблема вербализации эмоций человека как Homo sapiens является в современной лингвистике тем исследовательским фокусом, в котором перекрещивается ряд ее парадигм: коммуникативная, когнитивная, текстовая, прагматическая, культурологическая, категоризационая и др.» (Shakhovskiy, 2008: 24).

Проблема номинации до сих пор остается одной из ключевых проблем науки о языке. Однако если в лингвистике она требует, скорее, теоретической, концептуальной разработки, практическое решение проблемы номинации является вопросом необычайно острым в различных, особенно гуманитарных, дисциплинах.

Как известно, «культурная и этническая идентичность каждого языкового коллектива складывается в течение длительного исторического времени и имеет истоки в прошлом» 'Cultural and ethnic identity of each language community develops over a long historical time and has origins in the past' (Erofeeva, 2014: 438). В большинстве случаев попытка этимологизации лексем, называющих душевное состояние человека, позволяет выявить некий конкретный (как правило, физический) признак, который некогда лег в основу наименования психического феномена (волнение, раздражение, стыл, трепет и др.). Мы используем термин душевное состояние как общее нерасчлененное обозначение эмоций, чувств и состояний (Letyagova, 2005), о трактовке состояния как семантической категории в широком ономасиологическом смысле см. (Kosova, 2014). В этой связи представляется необходимым отметить, что «именно «душа», а не «разум», «сердце», «голова» является важным и уникальным понятием для русской <..> культуры и воспринимается как вместилище для внутренних состояний человека» (Gilazetdinova, 2014: 69).

Однако на современном этапе развития языка слова, именующие душевные состояния, относятся к группе абстрактной лексики. В связи с этим номинация душевного состояния и, наоборот, семантизация лексем, вербализующих душевный мир человека, вообще необычайно трудны даже для лингвистов, а тем более - для обычных носителей языка (Akhmerova, 2010).

Таким образом, очевидно, что «разговор о чувствах» для современного человека - это своеобразный ментальный вызов, ответить достойно на который можно только при наличии языкового чутья, большого словарного запаса и желания по-настоящему понять собеседника. Однако способность говорить о своем душевном состоянии, подбирая для этого наиболее точные лингвистические средства, - насущная необходимость современного человека, который ежедневно испытывает большое количество разнообразных эмоций, 
будучи участником разных «коммуникативных потоков». Адекватная вербализация душевных состояний является часто залогом успешной коммуникации.

Речевая коммуникация - это «стратегический процесс, базисом для него является выбор оптимальных языковых ресурсов» (Issers, 2008: 10), причем «всегда есть разные способы сказать об одном и том же, и выбор никогда не бывает случайным» (Fowler, 1991: 4). Следовательно, языковое варьирование при вербализации душевного состояния несет большую смысловую нагрузку.

\section{Психологический дискурс в современном русском языке}

Вероятно, можно говорить о существовании в современном русском языке особого «психологического» дискурса, поскольку «разговор о чувствах» предполагает не только вербальную составляющую, но и специфический набор прагматических характеристик (настрой собеседников, время и место, цели и мотивы и др.). Мы предлагаем выделять две его разновидности: психотерапевтический дискурс и обиходный психологический дискурс.

В психотерапевтическом дискурсе коммуникантами являются психолог-профессионал (носитель научной картины мира, владеющий научной терминологией) и клиент (обычный носитель языка, мотивированный на максимально прямую вербализацию душевного состояния, что в том числе предполагает предпочтительность вербальных средств коммуникации).

Эта мировоззренческая разница затрудняет достижение коммуникативной цели и требует и от клиента, и от терапевта большого лингвистического мастерства. Следовательно, языковому коду придается особая значимость, он является важнейшим диагностическим и в то же время «лекарственным» средством. (Особенности психотерапевтического дискурса были описаны нами довольно подробно в (Akhmerova, 2010), поэтому в данной работе мы лишь ссылаемся на некоторые актуальные для нашего исследования выводы и наблюдения).

Говорить о психическом мире можно лишь в том случае, если он вербализован, если сформулирована проблема, если описано душевное состояние. Однако именно в области номинации душевных состояний носители языка испытывают значительные затруднения (Akhmerova, 2009; Makarov, 2002), а значит, палитра наименований (и непосредственных переживаний) психологических явлений оказывается обедненной.

Обиходный психологический дискурс, в отличие от терапевтического, имеет дело с состояниями человека «здесь и сейчас», поэтому почти не остается времени для рефлексии и, тем более, саморефлексии, и сложные отношения между миром переживаний и миром слов проявляются наиболее полно. В этом типе дискурса предполагается общение самых разных индивидов, их социальные роли и мировоззренческие типы не заданы заранее. Мы можем предполагать, что в подобной коммуникации невербальные средства коммуникации и косвенные способы вербализации душевного состояния очень частотны, поскольку обиходный психологический дискурс ориентирован прежде всего на выражение душевного состояния, тогда как психотерапевтический - на его осознание и принятие.

Таким образом, предмет нашего исследования - особенности вербализации душевного состояния как дискурсивный маркер в современном русском языке.

Исследование проводится на материале анализа материалов психотерапевтических сеансов, зафиксированных в книге психотерапевта Е. Михайловой «"Я у себя одна", или Веретено Василисы» и языка романа 
А.Иванова «Географ глобус пропил», причем в последнем нас интересуют только контексты с прямой речью героев, которые, по нашему мнению, максимально приближены к разговорной речи. Внешний сюжет романа строится на описании взаимоотношений и взаимодействий главного героя с членами семьи, коллегами, учениками и друзьями, что, естественно, подразумевает погружение читателя в мир различных внутренних состояний, которые имеют различные соответствия в вербальном языке. Следует отметить, что подавляющее большинство вербализаций в обоих источниках представляет собой экспликацию негативного душевного состояния.

В лингвистической литературе языковая экспликация душевного состояния являлась объектом исследования. В.И. Шаховский предлагал выделять три разновидности эмотивной лексики: номинативы (прямые номинации душевных состояний - злость, боюсь, ревную, обиделся и др.), дескриптивы (описательная передача эмотивной семантики - коленки трясутся, внутри все кипит и т. д.) и экспликанты (слова с яркой коннотацией - Подлец! Негодяй!) (Shakhovskiy, 2008). Эта классификация актуальна и для нашего исследования.

Мотивируемый прагматической установкой, говорящий использует все богатство доступных ему языковых средств (как вербальных, так и невербальных, однако нас будут интересовать прежде всего первые).

1. Номинативы в психотерапевтическом дискурсе довольно частотны (клиент мотивирован прагматической установкой на использование прямых номинаций душевных состояний, насколько позволяет его лингвистическая эрудиция): Когда ты заговорила о ситуаџии, которую не любишь вспоминать, я впервые испугалась по-настоящему (Mikhailova, 2003: 35) и др.

Психологи отмечают, что «удачная» номинация проблемного душевного состояния - уже путь к решению проблемы (правильная диагностика состояния «подсказывает» решение: если это страх, необходимо предпринять активные действия, если печаль, потребуется внутренняя работа, чтобы пережить и «отпустить» ситуацию и т. п., см. (Akhmerova, 2009)).

В психологии реальное подтверждение получает лингвистический постулат о том, что мы видим мир таким, каким он предстает в нашем языке. «Власть» названия над нашим сознанием и подсознанием настолько велика, что существует прием «переименования» симптома. По словам психотерапевта Дж. Энрайта, «мы часто имеем возможность найти новое название для симптома или вызывающей отрицание особенности поведения - название, описывающее это поведение не менее точно, чем первоначальное, но обладающее позитивным качеством. Так, если отрицаемой чертой может быть упрямство, то новым наименованием может быть упорство. Термины описывают одно и то же поведение, различна только оценка. Во время поиска нового названия пациент ясно переживает тот факт, что он сам приписывает то или другое ценностное значение событию, о котором идет речь» (Enrait, 2002: 254). В данном контексте переименование - это путь к исцелению.

Если в психотерапевтическом дискурсе представлены, в основном, прямые номинации душевных состояний самого говорящего, то в обиходном психологическом дискурсе они довольно редки и соотносятся с душевными состояниями других людей (не говорящего): Ну что ты в бутылку лезешь? На меня остервенилась, Ветку на все корки разделала.../ A ты не зли меня и алкашей своих не подсовывай! (Ivanov, 2007: 210) и др. 
В связи с этим можно заметить, что здесь перед нами, по словам Дж. Энрайта, «значимые установки, скрытые в языке». По его мнению, важно отслеживать навязчивое использование оборотов, которые выносят источник действия за пределы говорящего. Энрайт так обращается к человеку, злоупотребляющему подобными конструкциями: «Ты живёшь в странном мире; такое впечатление, что все начинается вне тебя. Где же ты во всем этом?» Так, для усиления ощущения присутствия очень полезно совершить «обряд» принятия ответственности за все то, что произнесено или сделано, и в этом помогает использование формы первого лица: «Ты уже утомил всех!» - «Я чувствую, что раздражен твоими словами» и др. Таким образом человек, по мнению Энрайта, учится принятию ответственности за свои чувства и их аутентичности (Enrait, 2002: 84).

Мы зафиксировали единичные примеры, в которых герой повествует о своих чувствах, но это, как правило, касается прошлых событий: Попыттался $я$ Ветке мозги прочистить, она и ляпнула мне: не суйся, мол, и катись отсюда. Я, понятно, разозлился благородно (Ivanov, 2007: 84). Вероятно, по прошествии времени, легче осознать и принять собственные негативные чувства.

В обеих разновидностях психологического дискурса преобладают названия негативных душевных состояний, а, как известно, человеческое сознание скорее «замечает» не норму, а отклонение от нормального, что является семантической универсалией.

\section{2. Дескрипторы}

Психотерапевтический дискурс

А. Описание телесных ощущений.

1. Использование лексики, прямо указывающей на телесное ощущение: Я на своем месте, мне легко дышится, мои глаза широко открыты, руки пока просто перебирают материал, но в любую секунду готовы заработать (Mikhailova, 2003: 304) и др.

2. Использование семантически трансформированной лексики (концептуализация душевного состояния): У тебя все получается, ты летаешь, ты горы можешь свернуть. Как будто у тебя роман не с человеком, а со всем миром... (Mikhailova, 2003: 116) и др.

Б. Описание проблемной экстралингвистической ситуации (этот способ вербализации душевного состояния со всеми его особенностями характерен и для обиходного психологического дискурса).

Часто сигналом психологической проблемы является наличие вызывающей психологический дискомфорт ситуации или невозможность желаемого или необходимого действия. В этом случае диагностика душевного состояния еще более усложняется (без дополнительных вопросов довольно трудно определить, что именно чувствует клиент в следующем контексте cmpax, раздражение, стыд или другое, в некоторой степени этот недостаток характерен и для предыдущего способа вербализации - указания на соматику): Он стар, он скоро уйдет, а мы до сих пор не можем научиться разговаривать по-человечески (Mikhailova, 2003: 173) и др.

В обиходном психологическом дискурсе в качестве способа вербализации негативного душевного состояния выступает речевой жанр ссоры, являющейся разрешением сюжетообразующего конфликта.

Ссора, будучи одним из наиболее распространенных комплексных жанровых образований, «предоставляет говорящему широкий спектр языковых возможностей и обладает соответственно наибольшими по сравнению со смежными жанрами конфликтогенными средствами» (Rabenko, 2013: 83). Правила внутреннего развития ссоры «предоставляют коммуникантам 19

XLinguae Journal, Volume 8 Issue 4, October 2015, ISSN 1337-8384 
определенную свободу речевого поведения», что отражается «в выборе внутрижанровых тактик, то есть комплекса языковых единиц, оптимальных для достижения цели коммуникации» (Rabenko, 2013: 84).

Нами были отмечены тактики возмущения (Тоже мне барин вылскался - стол ему накрывай да наряжайся!.. Я еще посмотрю, какой он. Больно он мне подозрителен...), обвинения (Tbl эгоист - страшно подумать какой!), упрека (Тут у крана ишачу, а ты пальцем не шевельнёшь) (Ivanov, 2007).

Исследователи отмечают активное использование в речевом жанре ссоры инвективной лексики и, соответственно, тактики оскорбления, однако, по нашим наблюдениям, в языке «интеллигентных», образованных людей (каковыми себя считают герои) ссора (например, между мужем и женой) может в языковом плане строиться и на вполне нейтральной лексике. Количество стилистически маркированных слов по сравнению с общим языковым массивом конфликтного контекста невелико (ищачить, нажираться, вылскался, спятить и др.). Следовательно, вся смысловая нагрузка по экспликации негативного душевного состояния ложится на форму языкового воплощения - сам речевой жанр ссоры, а также на невербальные средства коммуникации (тон, громкость, интонация и др. особенности невербального поведения, например: Надя $c$ досадой грохнула в шкафу плечиками и др.):

(1) Надя мыла посуду, а Служкин сидел за чистым столом и пил чай.

- $\quad$ Тут у крана ишачу, а ты пальцем не шевельнёшь (упрек), ворчала Надя...Неизвестно, о чем только думаешь...

- $\quad$ Почему не известно? Известно. О тебе с Татой.

- $\quad$ Если бы обо мне думал, то взял бы да и помог (упрек).

- Давай помогу, - согласился Служкин. - Отходи от раковины.

- П Поздно уже, - мстительно ответила Надя. - Сразу надо было (упрек).

- Так я же Татку спать укладывал...

- Полтора часа? У меня она всегда за пять минут засыпает

(упрек).

- Я Я ей книжку читал - она слушала.

- Баловство всё это! - упорствовала Надя. - Изображаешь перед ней заботливого папочку, да? Был бы заботливый, не таскал бы в дом кого попало, сам бы как свинья не нажирался ...(упрек + обвинение) (Ivanov, 2007: 21).

В данном примере полностью отсутствует как инвективная лексика, так и собственно номинации отрицательных душевных состояний, которые испытывает героиня (возмущение, обида и др.). Эта же особенность характеризует и прочие аналогичные контексты (ссоры мужа и жены).

Интересно, что носители языка безошибочно «считывают» неназванные, но подразумеваемые негативные душевные состояния:

(2) Служкин тяжело вздохнул и виновато попросил:

- Давай, Надя, достанем нашу бутылку...

- Доставай, - подчеркнуто-безразлично ответила Надя. - Ты же пьешь, а не я-чего спрашивать?

- Мы в честь знакомства, Надюша, - поддержал Будкин. - Верно, Таточка?

- Полчаса как познакомились, а уже «Надюша», «Таточка»...

Служкин молча потянулся к шкафу и достал бутылку водки.

- Надя, не злись, сядь, - позвал он.(Ivanov, 2007: 19). 
В примере (2) можно отметить любопытный способ невербальной экспликации обиды и возмущения - подчеркнутое безразличие в голосе и поведении, которое, однако, безошибочно понимается собеседниками как выражение гнева.

Отсутствие прямых номинации негативных душевных состояний, на наш взгляд, следует рассматривать в контексте метанаучного подхода, привлекая данные психологии. Так, с точки зрения транзактного анализа (одной из психологических моделей анализа поведения человека), индивид всегда действует, исходя из интересов и возможностей своих эго-состояний: Ребенка, Родителя или Взрослого. Позиция Взрослого характеризуется осознанностью, здравым восприятием реальности, находясь на этой позиции, можно противостоять психологической манипуляции. Позиция Ребенка поддерживает все естественные побуждения личности, а позиция Родителя проявляется в критическом отношении к окружающим (вследствие чего они часто «спускаются» на детскую позицию и испытывают чувство вины, легко становясь жертвой психологической игры) (Bern, 2006). С этой точки зрения очевидно, что использование прямых номинаций негативных душевных состояний (я злюсь, чувствую раздражение, это возмущает меня и др.) подразумевает осознание говорящим своего состояния (т.е. это позиция Взрослого), что может привести и к изменению поведения (см. (Akhmerova, 2009); о предпочтительности использования форм первого лица см. выше).

По всей видимости, само отсутствие прямых номинации негативных душевных состояний знаково и свидетельствует о нежелании говорящего действовать исходя из позиции психологического Взрослого. Так, в примере (1) упреки и обвинения со стороны Нади (позиция Родителя) вынуждают Служкина встать на позицию Ребенка, начать оправдываться, почувствовать себя виноватым. Ситуация не разрешается, собеседники не находят сути проблемы, хотя очевидно, что в данном случае дело вовсе не в посуде.

3. Экспликанты в психотерапевтическом дискурсе в силу специфики ситуации общения не представлены. В обиходном психологическом дискурсе они присутствуют как неотъемлемый элемент языкового наполнения конфликтных контекстов:

Служкин наклонился кего оттянутому уху и шепнул:

- Только дернись, гад, рожей в стенку суну (Ivanov, 2007: 94) и т.д.

\section{Заключение}

Таким образом, адекватная вербализация душевного состояния в психотерапевтическом и обиходном психологическом дискурсе - необходимое условие достижения коммуникативной цели и трудная задача, стоящая перед носителями языка. Ее осуществление затрудняется диффузным и абстрактным характером семантики слов, эксплицирующих в языке психологическое состояние, а также сложными отношениями человека с миром собственной психики и требует особого мастерства владения родным языком.

В обоих типах психологического дискурса нами были отмечены прямые и непрямые способы экспликации душевного состояния (по классификации В.И. Шаховского, соответственно - номинативы, с одной стороны, и дескриптивы и экспликанты, - с другой стороны).

Вероятно, номинации душевных состояний, помимо выполнения своего семантического «предназначения», являются еще и своеобразным дискурсивным маркером: так, они необходимы в психотерапевтическом дискурсе, где само их присутствие уже является одним из способов терапии; в обиходном психологическом дискурсе знаковым является их избегание, что, 
например, «способствует» конфликтогенности коммуникации и позволяет существовать различным манипулятивным техникам. Следовательно, дескриптивы в психотерапевтическом дискурсе являются своеобразной семантической базой для «рождения» прямой номинации, тогда как в обиходном психологическом дискурсе они обладают собственной коммуникативной значимостью, являясь благодатной почвой для конфликтных речевых жанров.

По нашему мнению, в свете изложенного материала можно попытаться ответить на «основной вопрос эмотиологии» о том, являются ли названия эмоции ярлыками для эмоций или же содействуют их созданию, следующим образом: наименования душевных состояний, безусловно, способствуют осознанию и принятию эмоций, однако избирательное отношение говорящего к акту подобной номинации очевидна.

В этой связи уместным и необходимым представляется нам предложенное В.И. Шаховским понятие интеллектуальности коммуникативной эмоциональности, на которую указывает «способность человека как языковой личности управлять вербальным выражением эмоций и пропускать их через ситуативные, социальные и пр. фильтры в процессе общения и, в зависимости от них, «упаковывать» одни и те же эмоции в различные языковые формы или вообще не «пропускать» их в язык» (Shakhovskiy, 2008: 23).

\section{Bibliograpic references}

AKHMEROVA, L.R. 2009. Naivno-psikhologicheskiye predstavleniya o gneve v russkoy yazykovoy kartine mira // Uchen. zapiski Kazanskogo universiteta. Ser. Gumanit. nauki. T. 151, kn. 6. Kazan, pp. 167-175.

AKHMEROVA, L.R. 2010. Sposoby verbalizatsii dushevnogo sostoyaniya v psikhoterapevticheskom diskurse // Uchen. zapiski Kazanskogo universiteta. Ser. Gumanit. nauki. T. 152, kn. 6. Kazan, pp. 180-187.

BERN, E. 2006. Transaktnyy analis v psichoterapii: Sistemnaya individualnaya i sotsial'naya psichoterapiya. M.: Akademicheskiy Proekt. ISBN 5829107414.

EKMAN, P. 2003. Emotions revealed: recognizing faces and feelings to improve communication and emotional life. NY: Henry Holt and Company. ISBN 08050 72756.

ENRAIT, D. 2002. Geshtalt, vedushiy k prosvetleniyu. M.: Aprel Press, Izd-vo Eksmo. ISBN 5699011978 .

EROFEEVA, I.V. 2014. Nominalization in linguocultural paradigm of chronicles. Life Science Journal; 11(11), pp. 438-442. ISSN 1097-8135.

FOWLER, R. 1991. Language in the News: Discourse and Ideology in the Press. London - N-York. ISBN 0415014190.

GILAZETDINOVA, G.KH. - BAGMANOVA, L.N. 2014. Lingvokulturologicheskiye osobennosti representatsii ponyatiya "dusha" v tvorchestve I.S. Shmelyova // Filologia i kultura (Philology and Culture). N 4 (38). Kazan, pp. 69-73.

ISSERS, O.S. 2008. Kommunikativnye strategii I taktiki russkoy rechi. M.: Izdatelstvo LKI. ISBN 9785382006987

IVANOV, A. 2007. Geograf globus propil. SPb.: Azbuka-klassika. ISBN 9785352 022238.

KOSOVA, V.A. 2014. Sistemnaya znachimost slovoobrazovatelnykh kategoriy v russkom yazyke. Kazan'.

LETYAGOVA, T.V. - ROMANOVA, N.N. - FILIPPOV, A.V. 2005. Tysyacha sostoyaniy dushi: kratkiy psikhologo-filologicheskiy slovar'. M.: Flinta: Nauka. ISBN 5893497147 
MAKAROV, V.V. - MAKAROVA, G.A. 2002. Transaktnyy analis - vostochnaya versiya. M.: Akademicheskiy proekt, OPPL. ISBN 5942500142.

MIKHAYLOVA, E.L. 2003. "Ya u sebya odna", ili Vereteno Vasilisy. M.: Nezavisimaya firma "Klass". ISBN 5863750499.

NORMAN, B. 2004. Teoriya yazyka. Vvodnyy kurs. M.: Flinta: Nauka. ISBN 9785 89349498 3, 9785020029941.

RABENKO, T.G. 2013. Ssora: rechevye taktiki zhanra i sredstva ikh yazykovoy realizatsii // Vestnik SamGu. №8/1 (109), pp. 83-88.

SHAKHOVSKIY, V.I. 2008. Lingvisticheskaya teriya emotsiy. M.: Gnosis. ISBN 9785942440190.

WIERZBICKA, A. 1997. Yazyk. Kultura. Poznaniye. M.: Russkiye slovari. ISBN 5 892160025.

WIERZBICKA, A. 1999. Emotions Across Languages and Cultures: Diversity and Universals. Paris: Cambridge University Press. ISBN 0521590426.

Words: 3347

Characters: 26056 (14,48 standard pages)

Assoc. Prof. Liliya R. Akhmerova, PhD.

Department of Applied linguistics

Institute of Philology and Intercultural Communication

Kazan (Volga region) federal university

18, Kremlyovskaya St., 420008 Kazan

Russia

lavolkins15@mail.ru

Prof. Gelinya Kh. Gilazetdinova, PhD.

Department of General Linguistics, Cultural Linguistics and Theory of Translation Institute of Philology and Intercultural Communication

Kazan (Volga region) federal university

18, Kremlyovskaya St., 420008 Kazan

Russia

ggilaz@mail.ru 